\title{
Differentiation of Pseudomonas aeruginosa strains by ribotyping: high discriminatory power by using a single restriction endonuclease
}

\author{
FLORENCE GRATTARD, B. POZZETTO, A. ROS and ODETTE G. GAUDIN \\ Laboratoire de Bactériologie-Virologie, Faculté de Médecine J. Lisfranc, rue A. Paré, 42023 Saint-Etienne Cédex 2, \\ France
}

\begin{abstract}
Summary. The genotypic diversity of 40 presumably epidemiologically unrelated strains of Pseudomonas aeruginosa belonging to nine different O-serotypes was analysed according to ribosomal DNA fingerprints. Ribotyping was performed with a digoxigenin-labelled DNA probe and four restriction endonucleases. Characteristic banding patterns of three to 12 bands were obtained with the different endonucleases. Among the 40 strains, eight, nine, 10 and 29 different ribotypes were differentiated with EcoRI, the combination EcoRI + HindIII, BamHI and PvuII, respectively. Poor correlations were noted between the results of serotyping and those of ribotyping. With the latter method, indices of discrimination were calculated for each enzyme from the data of the 40 unrelated strains : the values ranged from 0.678 for $E c o$ RI to 0.979 for $P v u I I$. Epidemiologically related samples were also tested; this enabled assessment of whether the method was able to cluster strains from a common origin with each of the enzymes tested. Ribotyping with $P v u I I$ endonuclease is proposed for screening large numbers of $P$. aeruginosa strains in epidemiological studies. Additional enzymes could be used to further increase the discrimination between isolates found to be indistinguishable with $P v u I I$ enzyme.
\end{abstract}

\section{Introduction}

Precise markers are required for the epidemiological investigation of bacteria in order to analyse relationships between strains. In the case of Pseudomonas aeruginosa, a number of phenotypic methods have been proposed, such as biotyping, O-serotype determination, phage and pyocin typing, or antimicrobial susceptibility; but these methods often fail to discriminate between distinct isolates. ${ }^{1}$

Genotypic methods were introduced recently to improve the differentiation of $P$. aeruginosa strains, including pulse-field electrophoresis ${ }^{2,3}$ or the use of DNA probes derived from the exotoxin A gene, ${ }^{4-6}$ from a pilin gene ${ }^{7}$ or from an elastase gene. ${ }^{8}$ Because of highly conserved rRNA sequences among the eubacteria, restriction fragment length polymorphism of rRNA genes (ribotyping) represents another powerful approach for discriminating strains between and within species. ${ }^{9-10}$ In studies with $P$. aeruginosa, this marker has been used as a complementary method to compare $P$. aeruginosa $\mathrm{O} 12$ isolates, ${ }^{11,12} \mathrm{O} 11$ isolates, ${ }^{13}$ or isolates from cystic fibrosis patients-most of them being untypable or polyagglutinable. ${ }^{14,15}$ Recently, the ability of this typing method to distinguish between epidemiologically unrelated strains of $P$. aeruginosa has been demonstrated, especially when a combination of four different endonucleases was used. ${ }^{\mathbf{1 6}}$

In this study, the use of a digoxigenin-labelled ribosomal DNA probe to discriminate between strains of different O-serotypes was evaluated, with emphasis on the importance of the choice of endonucleases in the discriminatory power of ribotyping when applied to the analysis of $P$. aeruginosa.

\section{Materials and methods}

\section{Bacterial strains}

Forty strains of $P$. aeruginosa were included in the study, belonging to the nine most common $\mathrm{O}$ serotypes $(1,3,6,9,10,11,12,13$ and 16) of $P$. aeruginosa isolated in our hospital (table). The ATCC reference strain 27853 is designated as strain 9. Isolates were identified as $P$. aeruginosa according to the results of the cytochrome $\mathrm{C}$ oxidase reaction, biochemical properties and growth at $42^{\circ} \mathrm{C}$. Biotypes and antibiotic susceptibilities were determined by a micro-method (Microscan; Baxter, Sacramento, CA, USA) with Neg Combo 5I panels. Isolates were serotyped by agglutination with commercial antisera (Diagnostics Pasteur, Marnes la Coquette, France) according to the International Antigenic Typing Scheme. Each serotype was represented by two to eight presumably epidemi- 
Table. Differentiation of 40 strains of $P$. aeruginosa belonging to nine different $\mathrm{O}$ serotypes according to rDNA fingerprints performed with various enzymes

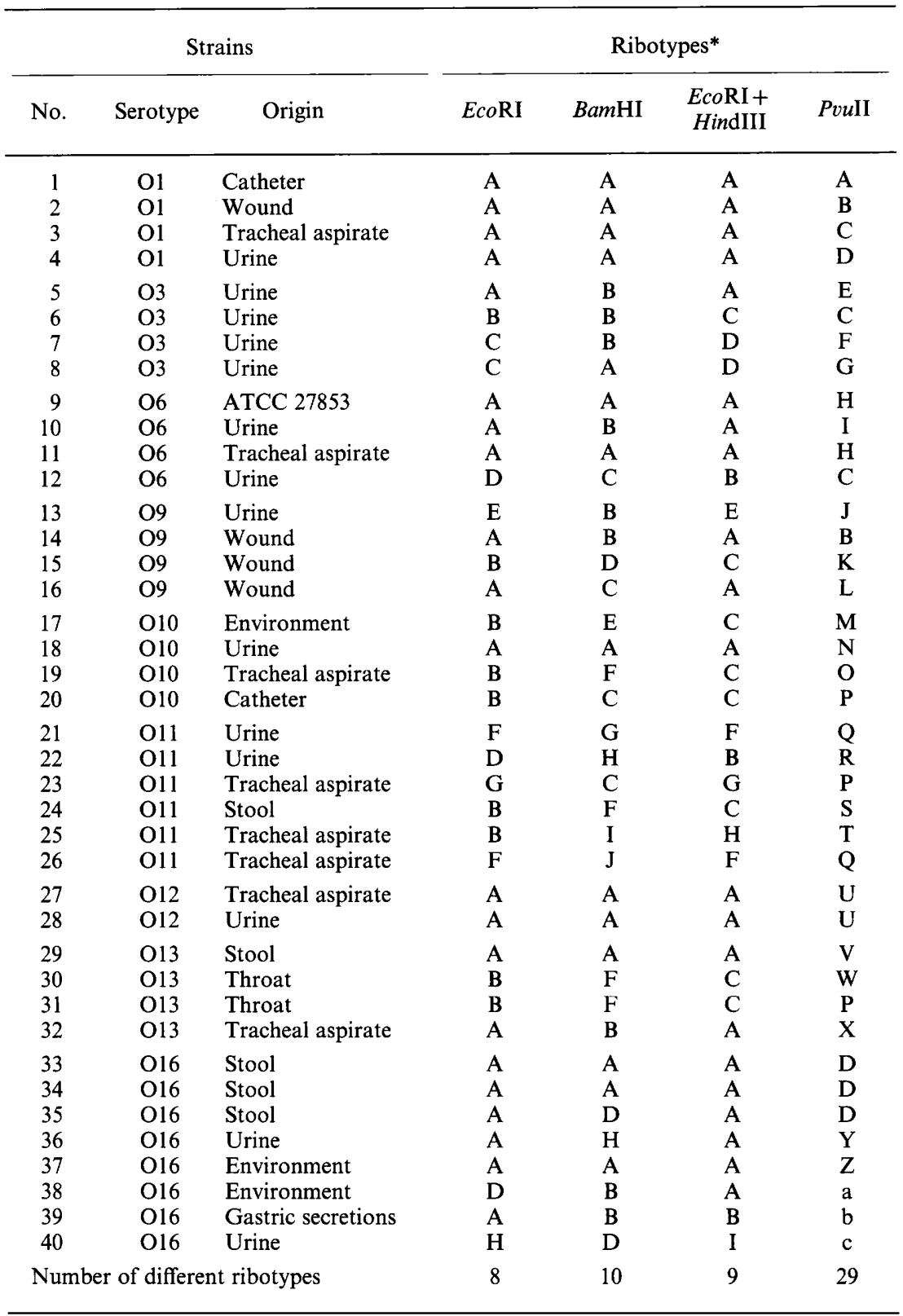

* $\mathrm{A}-\mathrm{Z}$ and a-c refer to the ribotypes illustrated in figs. 1,2 and 3.

ologically unrelated strains, which were isolated from patients (37 strains) or the environment (three strains) in different hospital units over a 5-year period. Strains 24 and 25 were isolated from the stools and the trachea of the same patient, but they showed very different biotypes and antibiograms, suggesting $a$ priori distinct clones of $P$. aeruginosa $\mathrm{O} 11$.

For two patients, six additional strains of $P$. aeruginosa $\mathrm{O} 11$ isolated from different clinical samples over a 1- or a 2-month period were investigated in order to apply ribotyping to epidemiologically related isolates. For the first patient, three isolates phenotypically related to strain 23 were tested. For the second patient, two sets of isolates were analysed: the first one-phenotypically related to strain 24 included two isolates, and the other-related to strain 25 - consisted of one isolate.

\section{$D N A$ restriction endonuclease analysis}

Chromosomal DNA was extracted by a method described previously. ${ }^{12}$ Briefly, bacterial colonies were lysed for $30 \mathrm{~min}$ at $37^{\circ} \mathrm{C}$ in a buffer $(50 \mathrm{~mm}$ Tris- $\mathrm{HCl}$, $50 \mathrm{~mm}$ EDTA, pH 8) containing $100 \mu \mathrm{g}$ of lyzozyme and $100 \mu \mathrm{g}$ of RNAase. Samples were treated successively for $30 \mathrm{~min}$ with $25 \mu \mathrm{l}$ of SDS $10 \%$ and $100 \mu \mathrm{g}$ of proteinase $\mathrm{K}$, at $37^{\circ} \mathrm{C}$ and $50^{\circ} \mathrm{C}$, respectively. DNA was purified by two successive phenol-chloroformisoamyl alcohol extractions and $3 \mu \mathrm{g}$ of chromosomal DNA was digested with EcoRI, HindIII, BamHI or $P v u I I$ according to the specifications of the manufacturer (Boehringer Mannheim, Meylan, France). Each extract was also submitted to a double digestion with $E c o$ RI + HindIII. DNA fragments were separated on an agarose $0.8 \%$ gel at $30 \mathrm{~V}$ overnight. Raoul I 

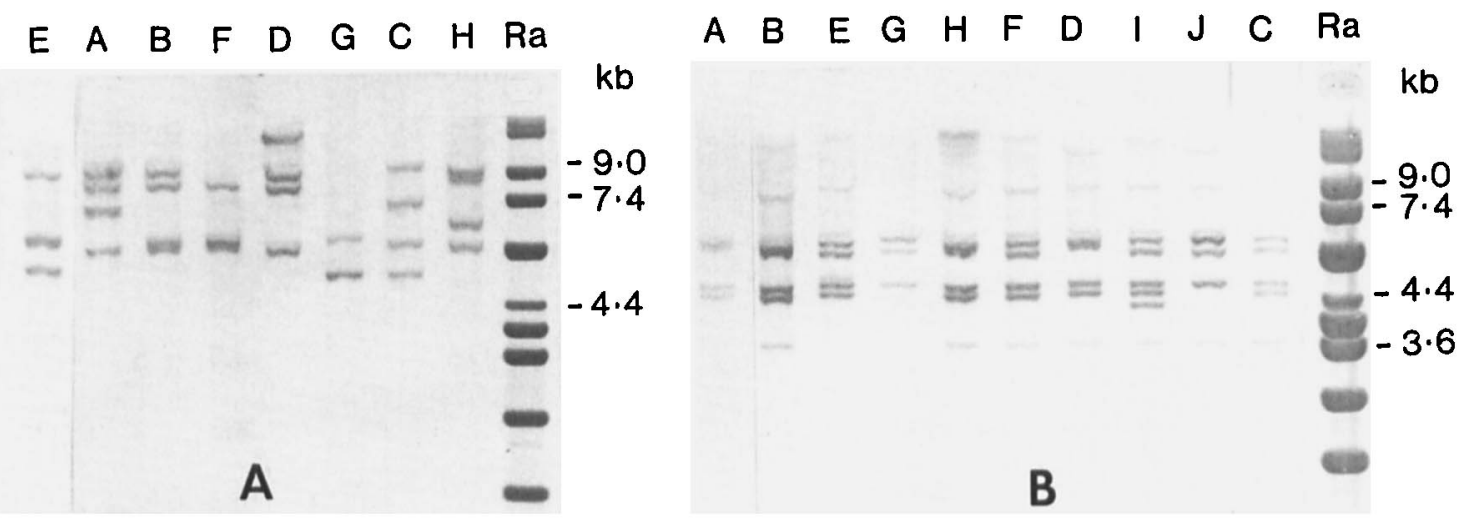

Fig. 1. Representative ribotypes of strains of $P$. aeruginosa with EcoRI (A) and BamHI (B). Letters A-H (A) and A-J (B) indicate the different profiles listed in the table. Lane Ra corresponds to size markers (in $\mathrm{kb}$ ).

(Appligene, Illkirch, France)-a mixture of linear DNA fragments from 0.23 to $48.50 \mathrm{~kb}$ - was used as a size marker. Restriction fragments were then transferred by Southern blotting to nylon membranes (Nylon N + ; Amersham, Les Ulis, France) for 1 hour by a Vacugene system (Pharmacia, Saint Quentin Yvelines, France).

\section{Ribotyping analysis}

Plasmid PKK3535, a PBR322 derivative containing the $r r n \mathrm{~B}$ ribosomal operon of Escherichia coli, ${ }^{17}$ was used as a probe and labelled with digoxigenin-11dUTP by random priming, as recommended by the manufacturer (DIG DNA Labeling Kit, Boehringer Mannheim). Hybridisation was performed at $42^{\circ} \mathrm{C}$ overnight in $5 \times$ SSC buffer containing $(1 \mathrm{ml})$ formamide $50 \%$, N-lauroylsarcosine $0.1 \%$, SDS $0.02 \%$, blocking reagent $4 \%$ and $20 \mathrm{ng}$ of rDNA digoxigeninlabelled denatured probe, as described previously. ${ }^{18}$ The membranes were then treated with antidigoxigenin antibodies conjugated to alkaline phosphatase. Ribosomal DNA banding patterns were revealed as purple-brown bands by the addition of substrate (nitroblue tetrazolium plus 5-bromo-4chloro-3-indolyl phosphate).

\section{Index of discrimination}

The discriminatory power of ribotyping is related to its ability to differentiate unrelated isolates. It was assessed for each enzyme by the determination of a numerical value called the discrimination index, which is based on the probability that two unrelated strains will be placed into different typing groups. This index was calculated by the equation proposed by Hunter and Gaston. ${ }^{19}$

\section{Results}

\section{Technical considerations}

In preliminary experiments with 18 isolates, EcoRI, HindIII, BamHI, PvuII and the combination EcoRI+
HindIII were compared for their abilities to discriminate between isolates. Since HindIII provided only three different patterns within the 18 strains, the enzyme was not used in further studies. Each strain was tested at least twice. Reproducible profiles were obtained, provided that a complete digestion of bacterial DNA by restriction endonucleases was performed; this was achieved by incubation for 3 hours at $37^{\circ} \mathrm{C}$. Moreover, when comparing the rDNA profiles of 12 strains belonging to serotypes $\mathrm{O} 1, \mathrm{O} 3, \mathrm{O} 6, \mathrm{O} 11$ or $\mathrm{O} 12$ after repeated subcultures, the ribotypes were found to be similar, demonstrating their stability across successive passages.

\section{Overall analysis of banding patterns}

Within the 40 strains of $P$. aeruginosa, EcoRI produced eight ribotypes (designated $\mathrm{A}-\mathrm{H}$ ) of three or four bands (fig. 1A). BamHI gave 10 ribotypes (A-J) of five or six bands (fig. 1B). The banding patterns obtained with EcoRI or BamHI were relatively clustered (4.8-9 kb and 3.6-14 kb respectively). The combination EcoRI + HindIII generated nine ribotypes (A-I) showing a core of common bands around $2.3 \mathrm{~kb}$ (fig. 2). PvuII provided 29 different profiles (designated $\mathrm{A}-\mathrm{Z}$ and $\mathrm{a}-\mathrm{c}$ ), as illustrated in fig. 3 and schematically redrawn in fig. 4 . The patterns exhibited seven to 12 well-separated bands of $2 \cdot 5-14 \mathrm{~kb}$. With this enzyme, all strains except those belonging to serotype $\mathrm{O} 12$ shared a common band of $2.5 \mathrm{~kb}$ (figs. 3 and 4).

\section{Analysis of ribotypes with regard to $O$-serotypes}

As shown in the table, the discrimination between the different $P$. aeruginosa $\mathrm{O}$-serotypes varied greatly according to the endonuclease chosen. With EcoRI, $B a m \mathrm{HI}$ and the combination Eco RI + HindIII, the most common ribotype (profile A) was shared by strains belonging to, respectively, eight, seven and eight O-serotypes out of the nine tested. By contrast, $P v u I I$ was able to discriminate between strains belonging to different serotypes, except for four profiles each shared by two (profiles B and D), or three (profiles $\mathrm{C}$ and $\mathrm{P}$ ) serotypes (table).

In addition, PvuII was able in most cases to 


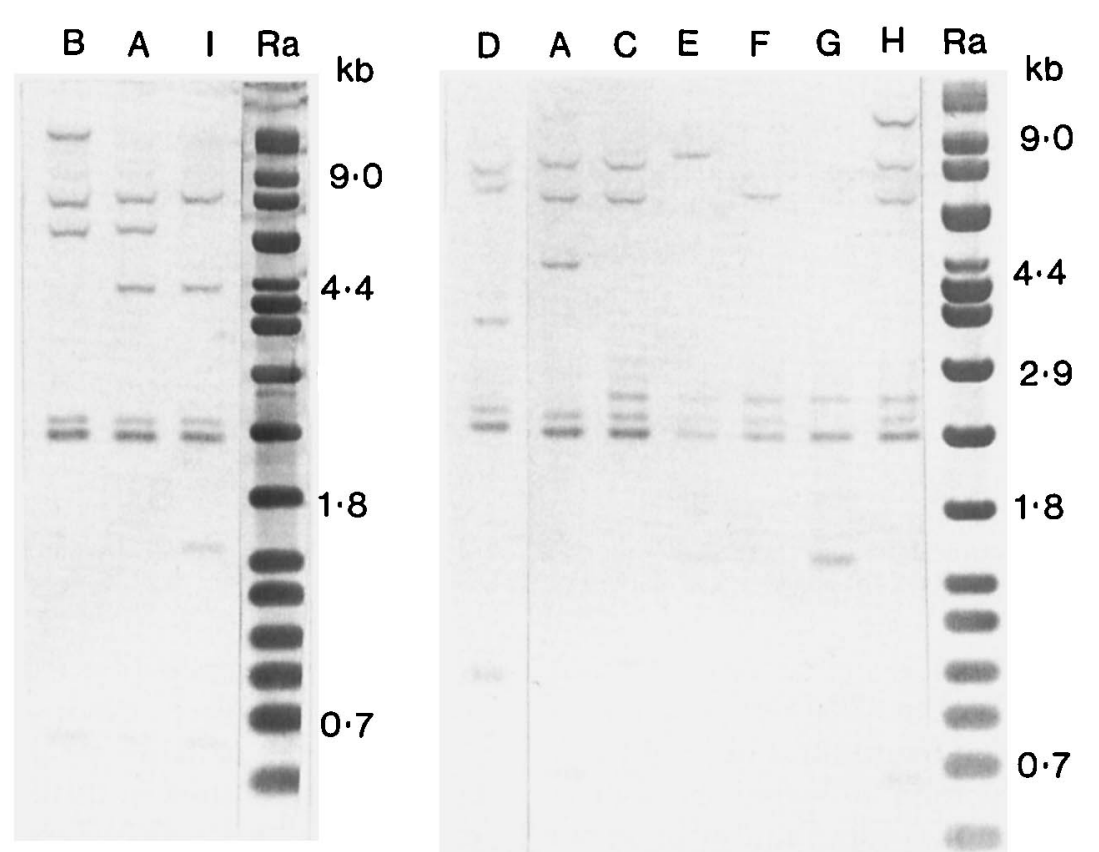

Fig. 2. Representative ribotypes of strains of $P$. aeruginosa with the combination $E c o$ RI + HindIII. A-I indicate the different profiles listed in the table. Size markers as in fig. 1.
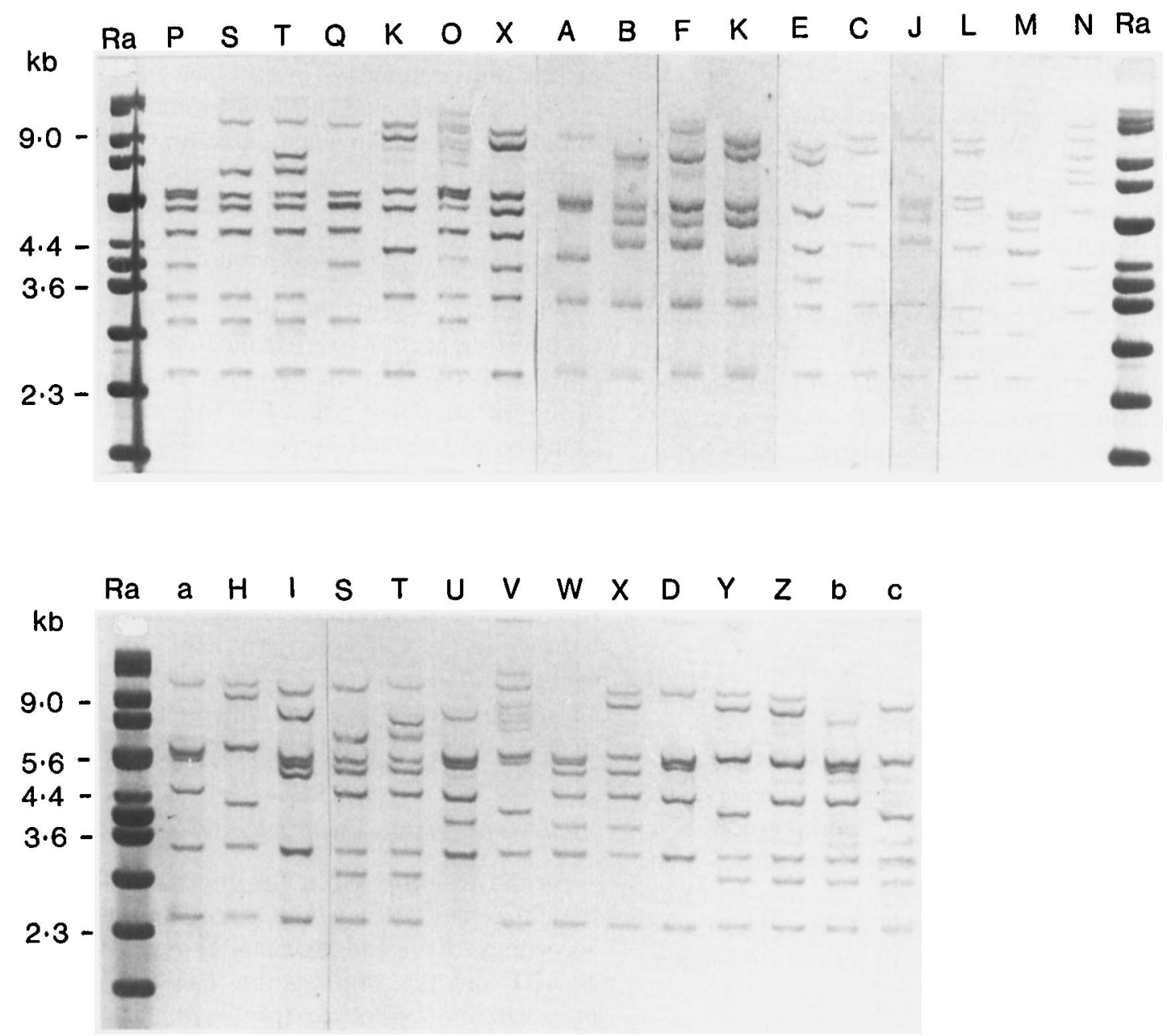

Fig. 3. Representative ribotypes of strains of $P$. aeruginosa with $P v u I I$. A-Z and a-c indicate the different profiles listed in the table. Size markers as in fig. 1.

differentiate strains within the same O-serotype, a feature shown much less frequently with the other endonucleases, as illustrated, for example, by the four strains of serotype $\mathrm{O} 1$ - all similar with EcoRI, BamHI or $E c o$ RI + HindIII but all different with PvuII (table). However, with the latter enzyme, a few strains shared the same profile: all the isolates belonging to serotype O12 exhibited similar patterns whatever the enzyme 


\section{Ribotypes}

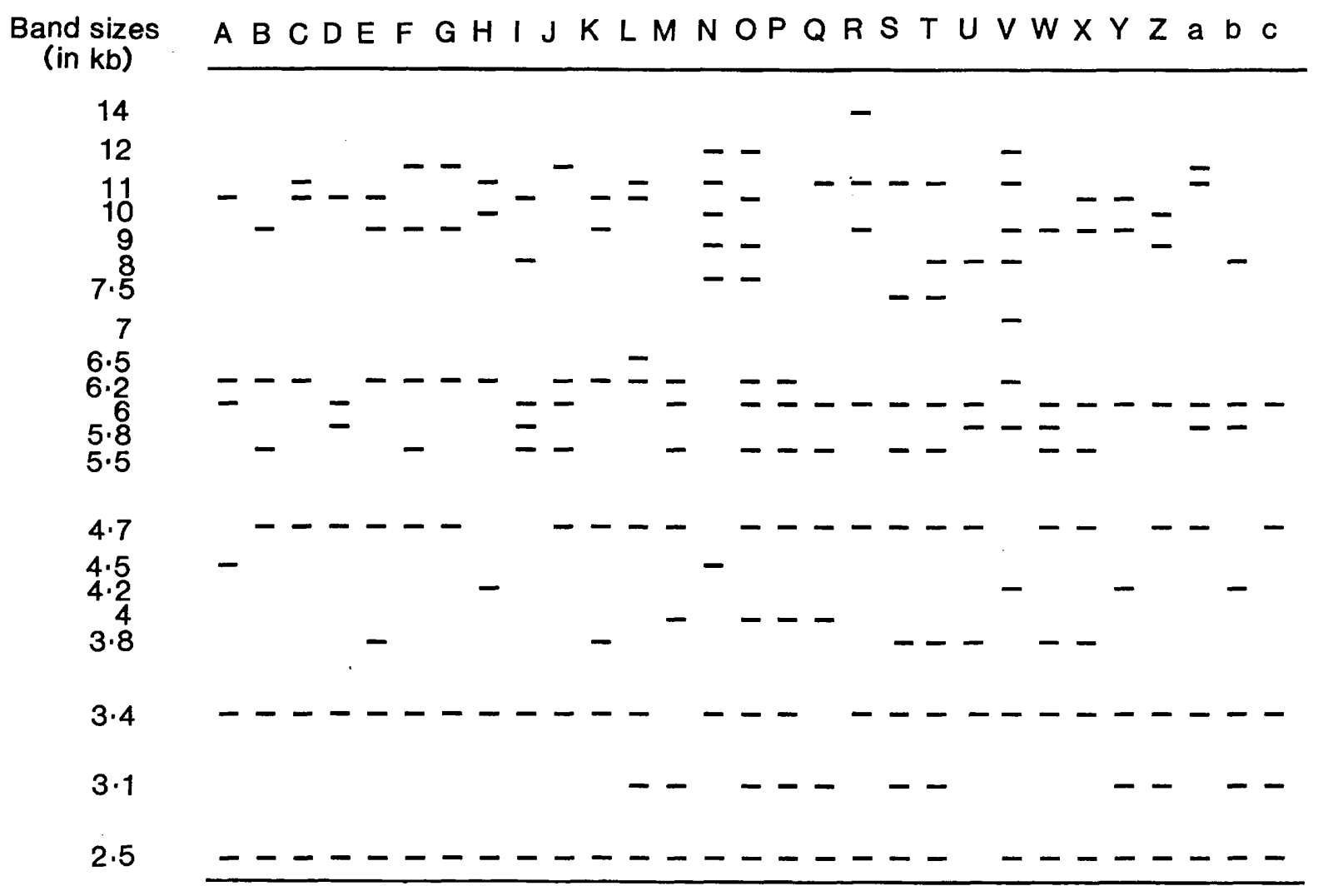

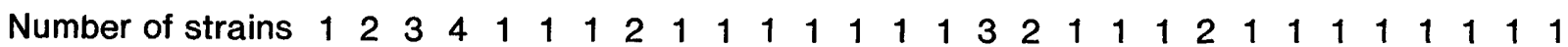

Fig. 4. Schematic representation of the ribotypes of the 40 strains of $P$. aeruginos $a$ with $P v u I I$. A-Z and a-c indicate the different profiles shown in fig. 3 and listed in the table.

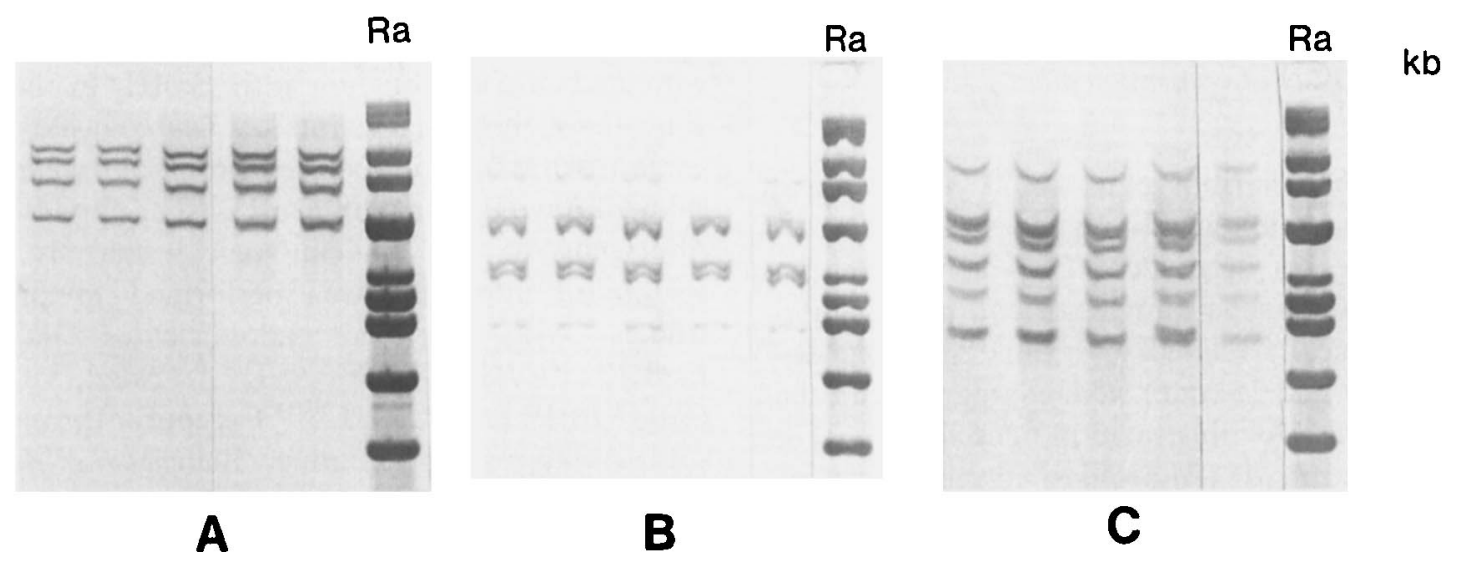

Fig. 5. Ribotypes of independent strains of $P$. aeruginosa O12, different from those listed in the table, with: A, EcoRI; B, BamHI; C, PvuII Size markers as in fig. 1.

tested. Only two strains are listed in the table, but additional isolates were tested with the same results, as illustrated in fig. 5 by the ribotypes of five other independent strains of the same serotype. Similar profiles were also observed with $P v u I I$ for two isolates (nos. 9 and 11) of serotype O6, also identical with the other enzymes, for three isolates (nos. 33, 34 and 35) of serotype O16 (two different profiles were obtained with BamHI), and for two isolates (nos. 21 and 26) of serotype $\mathrm{O} 11$ which were differentiated by BamHI profiles (table).
No relationship could be demonstrated between any ribotype and the sampling site of the specimens. As suspected from their phenotypic properties, strains 24 and 25 isolated from the same patient at different stages of his hospitalisation were of different ribotypes with all enzymes but one (EcoRI).

\section{Indices of discrimination}

For each enzyme, a discrimination index was calculated within the 40 epidemiologically unrelated isolates 


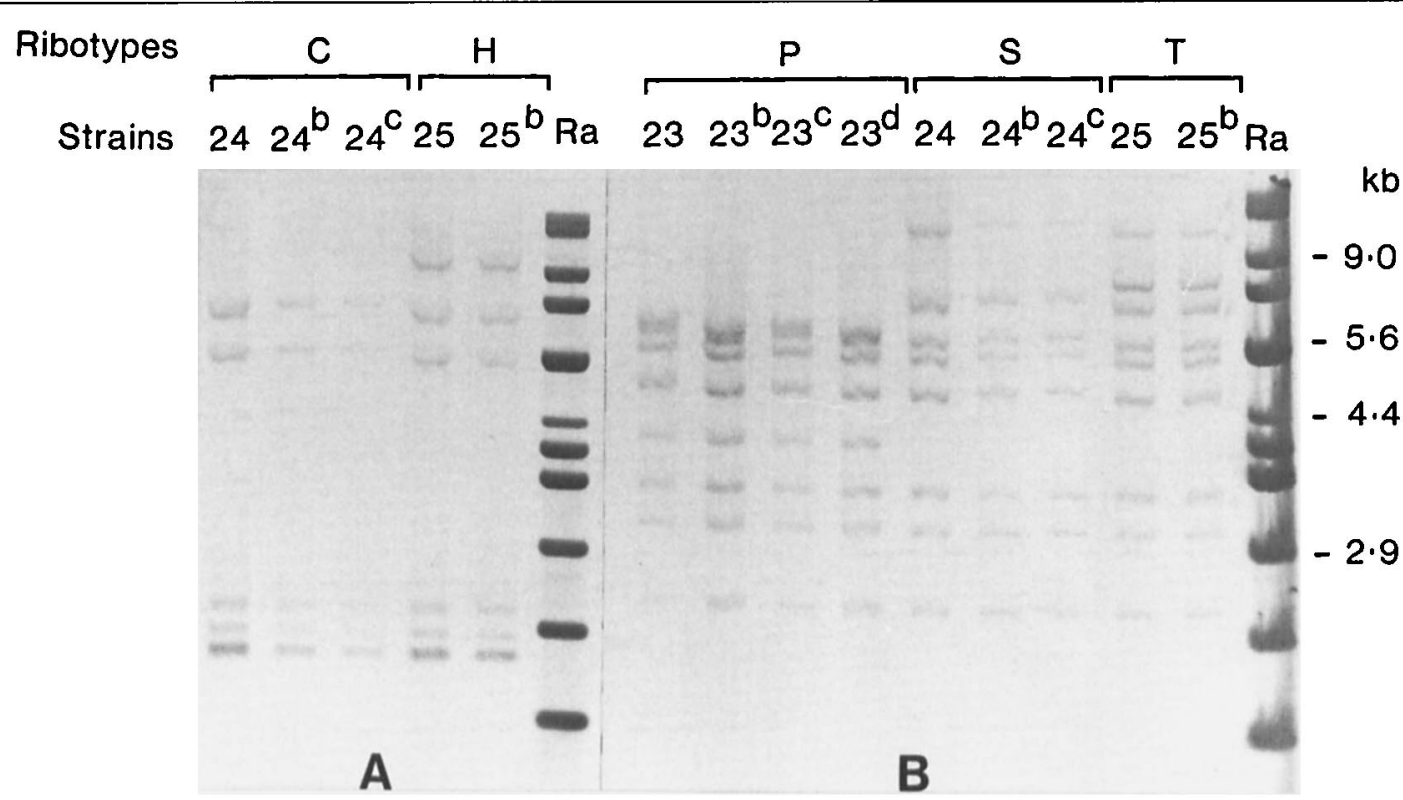

Fig. 6. Ribotypes of epidemiologically related strains of $P$. aeruginosa with $\mathbf{A}, E c o$ RI $+H i n d I I I$;,$P v u I I$. Different isolates belonging to three clones recovered from two patients were tested. Strains 23,24 and 25 correspond to those listed in the table. Strains $23^{\mathrm{b}}, 23^{\mathrm{c}}, 23^{\mathrm{d}}, 24^{\mathrm{b}}, 24^{\mathrm{c}}$ and $25^{\mathrm{b}}$ correspond to isolates phenotypically similar to strains 23,24 and 25 respectively. Size markers as in fig. 1.

of $P$. aeruginosa. This value reflected the discriminatory power of the method with regard to the endonuclease used. The indices ranged from 0.678 with EcoRI and 0.688 with EcoRI + HindIII to 0.816 with BamHI and 0.979 with PvuII. When the results obtained with PvuII were combined with those obtained with EcoRI + HindIII or BamHI, a slight increase in the discrimination indices was observed $(0.985$ and 0.989 respectively).

\section{Ribotyping analysis of epidemiologically related isolates}

To verify whether ribotyping would give identical patterns in epidemiologically related strains, six additional isolates of serotype 011 which had been isolated from successive samples of two patients and were phenotypically related to strains 23 (three isolates), 24 (two) and 25 (one) were compared with the different enzymes. As illustrated in fig. 6 for EcoRI + $H$ indIII (A) and PvuII (B) profiles, all related strains shared identical ribotypes with the four enzymes.

\section{Discussion}

Although no marker fulfils all the criteria of sensitivity, specificity and stability required for the epidemiological comparison of bacterial strains, ribotyping has several advantages over other molecular typing methods. The ribosomal genes located on the chromosome are not readily lost; the patterns are not influenced by antibiotic pressure and remain independent from phage or colicin production; the high conservation of ribosomal genes among all bacterial species allows the use of $E$. coli rRNA probes as a universal typing system $;{ }^{9}$ and the presence of several copies of the rRNA operon on the chromosome (four in the case of $P$. aeruginos $a^{20}$ ) is responsible for hybridisation patterns showing a reasonable number of bands (from three to 12 in this study). Moreover, the non-isotopic rDNA probe used in this study provided clear and sharp banding patterns, an advantage already noted by others. ${ }^{\mathbf{1 0}}$

The sensitivity of ribotyping depends greatly on the endonuclease used: Altwegg and Mayer ${ }^{10}$ demonstrated that strains of Salmonella can be differentiated with PstI or SmaI but not with EcoRI. In the same way, the rDNA fingerprints of Xanthomonas maltophilia isolates appeared more informative when studied with BamHI than with EcoRI. ${ }^{21}$ The application of ribotyping to the epidemiological analysis of $P$. aeruginosa infections was performed in previous studies with various endonucleases including EcoRI,$^{11-16}$ HindIII, ${ }^{11-15}$ BclI, ${ }^{14,15}$ SmaI,${ }^{11}$ SacI,${ }^{13}$ ClaI,${ }^{16}$ Pst $^{16}{ }^{16}$ and BamHI.$^{12,16}$ Except for three strains studied with $P$ stI in the study by Blanc et al. ${ }^{16}$ no more than six bands could be observed on the ribosomal patterns with each of these enzymes.

In our study, four different restriction enzymes or combination of enzymes were tested. EcoRI, which is known to have a high number of restriction sites on the bacterial chromosome, generated few bands on rDNA patterns; furthermore, the number of different ribotypes (eight) was limited. The combination of EcoRI and HindIII provided more recognisable fragments, allowing a better resolution of the profiles, as expected by the restriction sites of each enzyme on $P$. aeruginos ribosomal operon $;^{20}$ however, it failed to exhibit a higher number of different ribotypes. Like EcoRI, BamHI generated patterns with bands relatively clustered in size, but a better discrimination index was obtained with this enzyme than with EcoRI either 
alone or combined with HindIII. However, the most discriminatory patterns were provided by PvulI. The comparison of ribotypes generated by this enzyme was easy to perform with seven to 12 well-separated bands of 2.5-14 kb. Moreover, 29 different ribotypes were individualised with a very homogeneous distribution among the 40 strains, generating a high discrimination index of 0.979 , a value greater than that reported by Blanc et al. with the use of four restriction enzymes $(0.958) .{ }^{16}$ The strains of $P$. aeruginosa $\mathrm{O} 12$ exhibited identical ribotypes with all enzymes, confirming the genetic homogeneity of the $\mathrm{O} 12$ isolates in Europe shown in previous studies. ${ }^{11,12}$ It is worth noting that strains belonging to this serotype were the only ones not to give a $2 \cdot 5-\mathrm{kb}$ band on PvuII profiles. Other unrelated strains that exhibited identical ribotypes with PvuII were in some cases differentiated by ribotyping with either EcoRI + HindIII or BamHI, which contributed to a slight increase in discrimination indices ( 0.985 and 0.989 , respectively).

The data reported here also show that the correlation between results of ribotyping and those of serotyping is low, a finding already reported by Blanc et al. ${ }^{16}$ As a general rule, poor correlation has been noted between genotypic and phenotypic typing methods in $P$. aeruginosa isolates. ${ }^{4,6,16}$

To ascertain whether ribotyping was too discriminatory for clustering related strains in epidemiological studies, we investigated three groups of isolates with identical phenotypic properties in each group. Ribotyping was found to demonstrate genotypic relatedness among strains belonging to the same group with all enzymes, including PvuII.

These results show the importance of a careful choice of endonucleases to compare $P$. aeruginosa isolates according to their rDNA patterns. As previously noted by Blanc et al. ${ }^{16}$ the choice of the restriction enzymes is more important than their indefinite addition. Indeed, $P v u \mathrm{II}$ appears to be a very powerful tool for discriminating between strains of $P$. aeruginosa, and we suggest that this enzyme could be used alone for screening large numbers of isolates in epidemiological investigations. In a further step, one or two other enzymes (including BamHI) would be useful to assess the similarities observed with the first enzyme.

We thank Colette Villard for skilful technical assistance.

\section{References}

1. Pitt TL. Epidemiological typing of Pseudomonas aeruginosa. Eur J Clin Microbiol Infect Dis 1988; 7: 238-247.

2. Boukadida J, de Montalembert M, Gaillard JL et al. Outbreak of gut colonization by Pseudomonas aeruginosa in immunocompromised children undergoing total digestive decontamination: analysis by pulsed-field electrophoresis. $J$ Clin Microbiol 1991; 29: 2068-2071.

3. Grothues D, Koopmann U, Von der Hardt H, Tümmler B. Genome fingerprinting of Pseudomonas aeruginosa indicates colonization of cystic fibrosis siblings with closely related strains. J Clin Microbiol 1988; 26: 1973-1977.

4. Ogle JW, Janda JM, Woods DE, Vasil ML. Characterization and use of a DNA probe as an epidemiological marker for Pseudomonas aeruginosa. J Infect Dis 1987; 155: 119-126.

5. Kern W, Wolz C, Döring G. Molecular epidemiological study of Pseudomonas aeruginosa isolates from patients with acute leukemia. Eur J Clin Microbiol Infect Dis 1990; 9 257-261.

6. Fegan M, Francis P, Hayward AC, Fuerst JA. Heterogeneity, persistence, and distribution of Pseudomonas aeruginosa genotypes in cystic fibrosis patients. J Clin Microbiol 1991; 29: 2151-2157.

7. Speert DP, Campbell ME, Farmer SW, Volpel K, Joffe AM, Paranchych W. Use of a pilin gene probe to study molecular epidemiology of Pseudomonas aeruginosa. J Clin Microbiol $1989 ; 27: 2589-2593$.

8. Loutit JS, Tompkins LS. Restriction enzyme and southern hybridization analyses of Pseudomonas aeruginosa strains from patients with cystic fibrosis. J Clin Microbiol 1991; 29: 2897-2900.

9. Grimont F, Grimont PAD. Ribosomal ribonucleic acid gene restriction patterns as potential taxonomic tools. Ann Inst Pasteur Microbiol 1986; 137B: 165-175.

10. Altwegg M, Mayer LW. Bacterial molecular epidemiology based on a nonradioactive probe complementary to ribosomal RNA. Res Microbiol 1989; 140: 325-333.

11. Pitt TL, Livermore DM, Pitcher D, Vatopoulos AC, Legakis NJ. Multiresistant serotype O12 Pseudomonas aeruginosa: evidence for a common strain in Europe. Epidemiol Infect $1989 ; 103$ : $565-576$.
12. Grattard F, Gaudin OG, Pozzetto B, Ros A, Mbida AD. Genotypic homogeneity of nosocomial Pseudomonas aeruginosa $\mathrm{O} 12$ strains demonstrated by analysis of protein profiles, DNA fingerprints and rRNA gene restriction patterns. Eur J Clin Microbiol Infect Dis 1993; 12: 57-61.

13. Poh CL, Yeo CC, Tay L. Genome fingerprinting by pulsed-field electrophoresis and ribotyping to differentiate Pseudomonas aeruginosa serotype O11 strains. Eur J Clin Microbiol Infect Dis 1992; 11: 817-822.

14. Denamur E, Picard B, Goullet Ph, Bingen E, Lambert N, Elion J. Complexity of Pseudomonas aeruginosa infection in cystic fibrosis: combined results from esterase electrophoresis and rRNA restriction fragment length polymorphism analysis. Epidemiol Infect 1991; 106: 531-539.

15. Bingen E, Denamur E, Picard B et al. Molecular epidemiological analysis of Pseudomonas aeruginosa strains causing failure of antibiotic therapy in cystic fibrosis patients. Eur $\mathrm{J}$ Clin Microbiol Infect Dis 1992; 11: 432-437.

16. Blanc DS, Siegrist HH, Sahli R, Francioli P. Ribotyping of Pseudomonas aeruginosa: discriminatory power and usefulness as a tool for epidemiological studies. $J$ Clin Microbiol 1993; 31 : 71-77.

17. Brosius J, Ullrich A, Raker MA et al. Construction and fine mapping of recombinant plasmids containing the $r r m$ ribosomal RNA operon of E. coli. Plasmid 1981; 6: $112-118$.

18. Grattard F, Etienne J, Pozzetto B, Tardy F, Gaudin OG, Fleurette J. Characterization of unrelated strains of Staphylococcus schleiferi by using ribosomal DNA fingerprinting, DNA restriction patterns, and plasmid profiles. $J$ Clin Microbiol 1993; 31: 812-818.

19. Hunter PR, Gaston MA. Numerical index of the discriminatory ability of typing systems: an application of Simpson's index of diversity. $J$ Clin Microbiol 1988; 26: 2465-2466.

20. Hartmann RK, Toschka HY, Ulbrich N, Erdmann VA. Genomic organization of rDNA in Pseudomonas aeruginosa. FEBS 1986; 195: 187-193.

21. Bingen EH, Denamur E, Lambert-Zechovsky NY et al. DNA restriction fragment length polymorphism differentiates crossed from independent infections in nosocomial Xanthomonas maltophilia bacteremia. J Clin Microbiol 1991; 29: 1348-1350. 